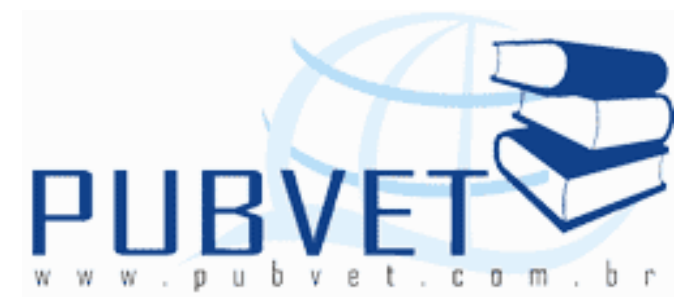

PUBVET, Publicações em Medicina Veterinária e Zootecnia.

\title{
Suplementação protéico-energética de bovinos de corte durante a época das águas
}

Patrícia Caires Molina ${ }^{1}$, Décio Souza Graça ${ }^{2}$, Lívio Ribeiro Molina ${ }^{3}$, Fabiano Alvim Barbosa ${ }^{4}$, Ana Luiza da Costa Cruz Borges ${ }^{2}$

${ }^{1}$ Mestre em Zootecnia, Departamento de Zootecnia, Escola de Veterinária, UFMG, Brasil

${ }^{2}$ Professor(a) Associado(a), Departamento de Zootecnia, Escola de Veterinária, UFMG, Brasil

${ }^{3}$ Professor Associado, Departamento de Clínica e Cirurgia, Escola de Veterinária, UFMG, Brasil

${ }^{4}$ Professor Adjunto, Departamento de Zootecnia, Escola de Veterinária, UFMG, Brasil

\section{Resumo}

A busca de uma estratégia de suplementação adequada tem como objetivo maximizar o consumo e a digestibilidade da forragem disponível, adequar o fornecimento de nutrientes ao requerimento nutricional e consequentemente maximizar o desempenho animal. A suplementação no período das águas por finalidade de aumentar a disponibilidade de energia e/ou do fornecimento de proteína, melhorando a digestibilidade da forragem e aumento o seu consumo.

Palavras-chave: desempenho animal, ganho de peso, pastagem. 


\section{Protein and energy supplementation of steers during the rainy season}

\section{Abstract}

The search for a proper supplementation strategy aims to maximize the intake and digestibility of forage dry adequate supply of nutrients to the nutritional requirement and consequently maximize animal performance. Supplementation during the rainy intended to increase the availability of energy and/or protein supply, improving the digestibility of forage and increase their consumption.

Keywords: animal performance, weight gain, pasture.

\section{INTRODUÇÃO}

A disponibilidade de recursos naturais no Brasil confere competitividade em comparação com outras nações exportadoras de alimentos. Dessa forma, a aplicação de tecnologias que otimize o desempenho animal é fundamental para a conquista do mercado de forma sustentável e competitiva. Para a produção de carne, é essencial eliminar as fases negativas de desenvolvimento, proporcionando condições ao animal para engordar durante todo o ano, a fim de alcançar peso de abate mais precocemente.

Os bovinos mantidos a pasto é importante o fornecimento adequado de uma dieta balanceada em energia, proteínas, minerais e vitaminas para promover desempenho satisfatório, independente da finalidade dos animais na propriedade, seja para reprodução ou para ganho de peso.

As pastagens tropicais apresentam períodos de alta produção forrageira na estação das chuvas e períodos de baixa produção durante a estação seca. $\mathrm{Na}$ maioria das vezes, as pastagens não contêm todos os nutrientes essenciais na proporção adequada, de forma a atender às exigências dos animais, mesmo considerando o período das águas. Por isso a utilização de algumas práticas de manejo tem sido adotada para minimizar as perdas ocorridas, como a 
utilização estratégica da suplementação energética, proteica ou energéticoproteica (Reis et al., 1997; Barbosa et al., 2007).

$\mathrm{Na}$ estação chuvosa, quando aparentemente as pastagens podem atender às demandas nutricionais dos animais, a suplementação de proteína e/ou energia pode ser benéfica para promover maior equilíbrio da dieta $e$, consequentemente, otimizar o desempenho animal.

Porto et al. (2009), afirmam que a suplementação dietética para animais com misturas múltiplas no período seco é prática comum pelos produtores, pois tem alta relação benefício/custo. Contudo, o uso desses suplementos durante o período das águas ainda é considerado por muitos como desnecessário, sobretudo quando se inclui nestas misturas compostos nitrogenados não protéicos, como a ureia. Isso tem sido amparado principalmente no fato de que, nessa época do ano, as forrageiras tropicais apresentam teores médios de proteína bruta (PB) que satisfazem as necessidades dos microrganismos do rúmen. Entretanto, para se manter uma curva contínua de crescimento dos bovinos e abater animais precoces alimentados basicamente de forrageiras tropicais, a utilização dessa prática nesse período pode ser recomendável (Sniffen et al., 1992).

A utilização de suplementação no período das águas tem a finalidade de aumentar a disponibilidade de energia, em função do aumento das concentrações proteicas das gramíneas e da alta taxa de degradabilidade ruminal desta fração, podendo causar um desequilíbrio na relação proteína/energia (Carvalho et al., 2003). Além do fornecimento de energia, em determinados períodos da estação chuvosa, pode haver deficiência de proteína na dieta de animais mantidos sob pastejo. Este trabalho tem como objetivo revisar a literatura sobre a viabilidade técnica da suplementação protéicoenergética para bovinos machos a pasto no período das águas. 


\section{REVISÃO DE LITERATURA}

\subsection{A PASTAGEM}

As pastagens tropicais e subtropicais são caracterizadas por uma rápida taxa de crescimento durante o período chuvoso, resultando em alta velocidade de amadurecimento, aumento da espessura da parede celular e induzindo valores de digestibilidade inferiores aos das gramíneas temperadas. Os animais em pastejo geralmente têm disponibilidade de forragem com elevado valor nutritivo por um período curto, pois com a chegada da estação seca, ou mesmo a deficiência pluviométrica durante o período das águas, a digestibilidade e o conteúdo total de nitrogênio decresce rapidamente (Kabeya et al., 2002; Carvalho et al., 2003).

De acordo com Paulino et al. (2001), a produção animal é função do consumo e valor nutritivo do alimento disponível. O consumo de alimentos é determinante no aporte de nutrientes para o atendimento dos requisitos de mantença e de produção dos animais. Assim, a produção por animal está diretamente associada com o consumo de matéria seca digestível (CMSD) representada pelas frações digestíveis de proteína, minerais, vitaminas e outros fatores nutricionais.

O aumento na eficiência de conversão de forragem em carne ou leite é conseguido quando a produção por animal é incrementada. Quando o CMSD aumenta acima do requerimento de mantença, maior quantidade de forragem ingerida é transformada em produto animal. Como exemplo, para recriar um bezerro de $150 \mathrm{~kg}$ de peso vivo até que atinja os $450 \mathrm{~kg}$ ao abate, com o ganho diário de $250 \mathrm{~g}$, seriam necessários $7320 \mathrm{~kg}$ de matéria seca de forragem, comparados a apenas $1903 \mathrm{~kg}$ de matéria seca se o ganho fosse de 1,1 kg diários (Tabela 1) (Blaser, 1994).

A forrageira a ser utilizada tem que atender pelo maior período possível às demandas dos animais. No entanto, se por um lado as forrageiras variam em 
qualidade, por outro, os requerimentos nutricionais do animal também não são constantes durante sua vida, ou mesmo no decorrer do ano. Estes variam em função de diversos fatores, como idade, estado fisiológico, sexo, grupo genético, peso e escore corporais (Euclides et al., 2000; Barbosa et al., 2008).

Tabela 1: Requerimento de matéria seca e proteína por um novilho para recria/engorda dos 150 aos $450 \mathrm{~kg}$ de peso vivo

\begin{tabular}{cccc}
\hline \multirow{2}{*}{$\begin{array}{c}\text { Ganho de Peso } \\
\text { diário }(\mathrm{kg})\end{array}$} & $\begin{array}{c}\text { Tempo Necessário } \\
(\text { dias })\end{array}$ & Matéria seca $(\mathrm{kg})$ & Proteína $(\mathrm{kg})$ \\
\cline { 3 - 4 } & 1200 & 7320 & 652 \\
0,25 & 600 & 4460 & 434 \\
0,70 & 400 & 3052 & 310 \\
1,10 & 273 & 1903 & 224 \\
\hline
\end{tabular}

Fonte: Adaptado Blaser (1994).

De acordo com a tabela 1 , se o animal ganhar $1,1 \mathrm{~kg}$ por dia significa menos tempo de permanência na propriedade com maior giro de animais e dinheiro na produção. Assim sendo, é importante o estabelecimento de padrões de crescimento dos animais e de práticas de manejo para cada sistema de produção, pois, cabe ao pasto suprir a maior parte ou a totalidade dos nutrientes para satisfazer as exigências nutricionais dos animais (Paulino et al., 2001).

\subsection{SUPLEMENTAÇÃO NAS ÁGUAS}

Na suplementação, deve ser estabelecida a associação de fontes de nitrogênio solúvel, minerais, fontes naturais de proteína, energia e vitaminas, visando 
proporcionar o desenvolvimento esperado dos bovinos em pastejo, além de aumentar a capacidade de suporte das pastagens (Barbosa et al., 2007). De acordo com Euclides et al. (2000), mesmo no período das águas as pastagens de Brachiaria decumbens e Brachiaria brizantha, sob pastejo contínuo, apresentam conteúdos de PB inferiores ao necessário para produção máxima que é de $12 \%$ para todos os propósitos em um rebanho de bovino de corte.

Novilhos em terminação suplementados durante as águas, normalmente, alcançam ganhos de peso médios adicionais de 100 a $200 \mathrm{~g} / \mathrm{animal} / \mathrm{dia}$. Nessa situação, qualquer tentativa de suplementação deve ser analisada em termos da meta a ser alcançada dentro de um determinado sistema de produção de carne (Thiago e Silva, 2001).

\subsection{SUPLEMENTAÇÃO ENERGÉTICA}

A forragem ingerida pelo animal muitas vezes pode ser deficiente em carboidratos prontamente fermentáveis para as bactérias do rúmen, que servem como fonte de energia para transformar a proteína ingerida em proteína microbiana. Havendo déficit de energia, ocorre excesso proporcional de nitrogênio, que é absorvido no rúmen, metabolizado no fígado e eliminado como ureia pela urina (Jones et al., 1988).

As variações no balanço de energia são dependentes do nível de ingestão de nutrientes digestíveis, sendo este influenciado por interações entre os alimentos. Nas pastagens com baixa disponibilidade de forragem a suplementação energética proporciona uma maior resposta animal. Ao contrário, se há oferta de forragem de elevada qualidade em abundância, ocorrerá resposta somente se a forragem for de baixo valor nutritivo, uma vez que ocorre alto nível de substituição (Paulino et al., 2001).

A suplementação energética no período das águas pode ter sua viabilidade econômica limitada pelo fato da possibilidade de ocorrer efeito de substituição (Paris et al., 2005). O animal deixa de ingerir energia proveniente da 
forragem, substituindo por energia do suplemento (Reis et al., 1997). Esse tipo de suplementação deve ser bem analisado, pois quando a oferta de proteína é alta, esta prática resulta na elevação da digestibilidade das forragens, resultando assim, em maior capacidade de suporte na propriedade, o que por sua vez, pode ser vantajoso. Deve-se neste caso ponderar o efeito de substituição e o custo da suplementação frente ao possível aumento do desempenho animal e da capacidade de suporte da propriedade (Euclides, 2001).

Paris et al. (2005), avaliaram as características de produção, o desempenho de novilhos mestiços em pastagem de coast-cross no período das águas, suplementados com duas fontes de energia: casca de soja (CS) e grãos de aveia (AV), onde foram fornecidos suplemento à $0,6 \%$ do PV com AV; suplemento à $0,6 \%$ do PV com CS; e suplemento à $0,3 \%$ do PV com AV + $0,3 \%$ do PV com CS (CSAV). Não houve efeito do tipo de suplemento sobre o GMD que variou de 0,667 (SS) a $0,840 \mathrm{~kg} / \mathrm{dia}$ (CS). Os autores concluíram que a suplementação de novilhos mestiços em pastagem de coast-cross, durante 0 período das águas com $0,6 \%$ do $\mathrm{PV}$, de grãos de aveia preta ou casca de soja, não refletiu melhoria no ganho médio diário e ganho de peso vivo por hectare.

Paulino et al. (2005), estudaram o efeito de diferentes fontes energéticas em suplementos múltiplos de auto regulação de consumo sobre o ganho médio diário (GMD), ganho de peso total (GPT) em novilhos recriados em pastejo no período das águas, com suplementos contendo grão de milho moído (GMM), milho desintegrado com palha e sabugo (MDPS), sorgo moído (SM) e tratamento controle (mistura mineral - MM). Embora não tenha sido verificada diferença estatística para o desempenho dos animais submetidos aos diferentes tratamentos, constatou-se superioridade no ganho médio diário de peso dos bovinos suplementados (em média 15\%) quando comparado aos animais não suplementados. Os autores verificaram ainda que o suplemento MDPS proporcionou ganhos adicionais em torno de $220 \mathrm{~g} / \mathrm{animal} / \mathrm{dia}$ em relação ao grupo controle, concluindo que essa resposta ocorreu por causa da 
eliminação dos efeitos associativos negativos entre forragem e grãos, proporcionados pelo atendimento total das exigências de proteína degradada no rúmen.

\subsection{SUPLEMENTAÇÃO PROTEICA}

Em um estudo sobre suplementação proteica Grings et al. (1994), observaram maior consumo voluntário de pasto no início do período chuvoso em relação ao final deste período. Isto sugere que o fornecimento de nitrogênio protéico favoreceu a digestão microbiana e aumentou a taxa de passagem devido a maior degradação microbiana, facilitando o escape de partículas do rúmen. Portanto, os autores concluíram que a suplementação proteica neste período pode ter retorno produtivo e econômico.

Minson e Wilson (1994) demonstraram que a suplementação proteica no final do verão pode aumentar a produção, mas as variações de composição da planta podem interferir com o consumo, podendo a resposta ser produtiva, mas antieconômica.

Porto et al. (2009), avaliaram o desempenho de novilhos mestiços HolandêsZebu em fase de recria recebendo suplementação com cinco fontes de proteína, em uma área de pastagem de Brachiaria brizantha, cv. Marandu, durante o período das águas. Os animais que receberam suplemento múltiplo apresentaram ganho médio diário de $211 \mathrm{~g} / \mathrm{animal}(23,78 \%)$ a mais que aqueles que receberam somente mistura mineral. Os autores concluíram que a suplementação múltipla proporcionou retorno econômico, independente da fonte de proteína utilizada.

Esses mesmos autores afirmaram ainda que os animais na suplementação com as misturas contendo farelo de soja apresentaram boa conversão do suplemento em quilograma de peso vivo (PV), mostrando a eficiência dos animais em transformar o suplemento adicional fornecido em quilograma de PV. A contribuição do efeito associativo positivo pode ter ocorrido entre o 
alimento concentrado e a forragem, uma vez que a forragem apresentava teor de $\mathrm{PB}$ de $8,99 \%$, valor que contribuiu para essa interação positiva entre os componentes da dieta e que pode aumentar tanto a digestibilidade quanto a quantidade de pasto consumido (Porto et al., 2009).

Segundo Del Curto et al. (1999), a resposta à suplementação proteica ocorre quando o teor de PB da forrageira é menor que 6 a $8 \%$. O uso de alimentação suplementar no período das águas é uma opção para o suprimento de nutrientes limitantes (Paulino et al., 2001) e favorece o aumento da eficiência de utilização das pastagens (Poppi e McLennan, 1995), reduzindo consideravelmente os ciclos de produção de bovinos em regime de pastejo, com possíveis retornos econômicos.

Zervoudakis et al. (2008), avaliaram a influência de suplementos múltiplos de autocontrole de consumo na recria de novilhos em pastagem de Brachiaria decumbens durante o período das águas e observou ganhos $20 \%$ mais elevados nos animais sob suplementação em comparação aos do grupo controle, o que resultou em ganhos adicionais de aproximadamente $200 \mathrm{~g} / \mathrm{dia}$, que são de grande relevância na intensificação da pecuária de ciclo curto em pastagens.

Durante o período das águas, Poppi e Mclennan (1995) ressaltaram que as gramíneas forrageiras geralmente não apresentam deficiência de PB. Contudo, a alta degradabilidade da PB da gramínea forrageira induz a perdas excessivas de compostos nitrogenados na forma de amônia diminuindo a disponibilidade de proteína para o animal aproveitar.

Villela (2004), avaliando o efeito de diferentes fontes de proteína durante o período das águas em pastagens de Brachiaria decumbens com teor de PB de $11,48 \%$, observou ganho médio diário de $855 \mathrm{~g} /$ animal, que foi $34 \%$ superior ao ganho dos animais do grupo controle ( $639 \mathrm{~g} / \mathrm{dia}$ ). O autor ressaltou que os ganhos adicionais obtidos nesta fase podem viabilizar o abate desses animais 
antes da segunda seca, ou seja, em torno de 20 meses de idade, o que, além de levar um giro mais rápido do capital, facilita o manejo na fazenda.

\subsection{SUPLEMENTAÇÃO ENERGÉTICO-PROTÉICA}

Moore et al. (1999) estudaram a interação entre volumosos e concentrados e verificaram que, na maioria dos casos em que houve suplementação, ocorreu aumento no ganho de peso diário. Segundo esses autores, o consumo de forragem aumentou com o uso do suplemento quando havia déficit de nitrogênio em relação à energia disponível. Segundo Acedo (2004), esses ganhos também são de grande importância na suplementação estratégica, visto que boa parte do lucro obtido na pecuária de corte nacional é fruto de oportunidade de venda do boi gordo em épocas de maior preço da arroba, e não somente da eficiência no processo produtivo. Esse mesmo autor, avaliando diferentes fontes de proteína sobre o desempenho de animais em recria durante o período das águas, não encontrou diferença significativa, embora tenham sido obtidos ganhos médios diários de até $180 \mathrm{~g}$ em relação ao controle, quando utilizado suplemento múltiplo à base de farelo de soja e farelo de glúten de milho.

Goes et al. (2003), ao avaliarem a suplementação a pasto de novilhos (Nelore) com peso inicial médio de $335 \mathrm{~kg}$, durante o período das águas, em pastagens de capim-gordura (Melinis minutiflora) e braquiária (Brachiaria radicans), utilizaram suplementação com sal mineral (SM), sal proteinado à base de milho, farelo de trigo e ureia (MT) e com sal proteinado à base de farelo de trigo e farelo de soja (TS). Os animais apresentaram ganhos médios de peso de 0,$60 ; 0,76$; e $0,88 \mathrm{~kg} / \mathrm{dia}$ para os suplementos SM, TS e MT, respectivamente, não havendo diferença entre os suplementos TS e MT. Portanto, os autores concluíram que os animais que receberam suplementação proteica no período das águas, apresentaram melhor desempenho, quando comparados aos que receberam a suplementação mineral. 
Cabral et al. (2008), avaliaram o efeito de diferentes níveis de suplementação sobre o desempenho de touros Nelore PO, durante o período das águas, submetidos aos tratamentos mistura mineral (T1); suplementação com concentrado na base de $0,2 \%$ do peso vivo (T2); suplementação com concentrado de $0,4 \%$ do PV (T3) e suplementação com concentrado de $0,6 \%$ do PV (T4). O concentrado utilizado foi composto de mistura mineral, fubá de milho, farelo de soja, casca de soja e ureia. O ganho de peso dos animais não foi influenciado pelo aumento do nível de suplementação, não diferindo do tratamento controle. Entretanto, os autores relataram que embora sem diferenças estatísticas, a oferta de suplemento no nível de $0,4 \%$ do PV propiciou GMD de $114 \mathrm{~g}$ a mais que o tratamento controle, ou seja, $10 \mathrm{~kg}$ de ganho de peso total a mais no período, o que permitiria aos animais serem abatidos com $450 \mathrm{~kg}$ de PV, 20 dias antes dos animais do grupo controle.

\section{CONSIDERAÇÕES FINAIS}

O fornecimento de suplementos no período das águas podem ser utilizados como estratégia para otimizar e maximizar a produtividade proporcionando ganhos elevados nos animais. Entretanto, a condição para a adoção do programa de suplementação dentro dos sistemas de produção deve atender a uma avaliação cautelosa de metas a serem alcançadas na propriedade em termos de desempenho animal.

A suplementação proteica nas águas pode ser recomendável quando ocorrem períodos de estiagem no período das águas, fenômeno denominado veranico, que reduz a concentração de proteína e pode comprometer a digestibilidade da forrageira. Essa restrição pode impactar negativamente o desempenho do animal, por não atender as exigências nutricionais.

Para a suplementação energética seu uso estaria associado ao aumento de aporte nutricional para as bactérias converterem a proteína bruta que chega ao rúmen em proteína microbiana. 
MOLINA, P.C. et al. Suplementação protéico-energética de bovinos de corte durante a época das águas. PUBVET, Londrina, V. 7, N. 1, Ed. 224, Art. 1489, 2013.

Embora os suplementos possam produzir efeito substitutivo, que resulta em aumento a capacidade de suporte das pastagens, diminuição do tempo de permanência na fazenda e giro mais rápido de capital mais rapidamente, a escolha da estratégia de suplementação deve ser baseada em cuidadosa avaliação técnica e econômica.

\section{BIBLIOGRAFIA}

ACEDO, T.S. Suplementos múltiplos para bovinos em terminação, durante a época seca, e em recria, nos períodos de transição seca-águas e águas. 2004. 58f. Dissertação (Mestrado em Zootecnia) - Universidade Federal de Viçosa, Viçosa.

BARBOSA, F.A.; GRAÇA, D.S.; MAFFEI, W.E.; et al. Desempenho e consumo de matéria seca de bovinos sob suplementação protéica- energética durante a época de transição água-seca. Arq. Bras. Med. Vet. Zootec., v.59, n.1, p.160-167, 2007.

BARBOSA, F.A.; GRAÇA, D.S.; GUIMARÃES, P.H.S.; et al. Análise econômica da suplementação protéico-energética de novilhos durante o período de transição entre água-seca. Arq. Bras. Med. Vet. Zootec., v.60, n.4, p.911-916, 2008.

BLASER, R. E. Manejo do complexo pastagem - animal para avaliação de plantas e desenvolvimento de sistemas de produção de forrageiras. In: Pastagens. Piracicaba: Escola Superior de Agricultura "Luiz Queiroz",1994, p.279- 335.

CABRAL, L.S.; ZERVOUDAKIS, J.T.; COPPEDÊ, C.M.; et al. Suplementação de bovinos de corte mantidos em pastagem de Panicum maximum cv. Tanzânia-1 no período das águas. Rev. Bras. Saúde Prod. An., v.9, n.2, p. 293-302, abr/jun, 2008.

CARVALHO, F.A.N.; BARBOSA, F.A.; MCDOWELL, L.R. Nutrição de bovinos a pasto.1ed. PaperForm, 2003, 428 p.

EUCLIDES, V.P.B.; CARDOSO, E.G.; MACEDO, M.C.M. et al. Consumo voluntário de Brachiaria decumbens cv. Basilisk e Brachiaria brizantha cV. Marandu sob pastejo. Revista Brasileira Zootecnia, v.29, supl.2, p.2200-2208, 2000.

EUCLIDES, V. P.B.; EUCLIDES FILHO, K.; COSTA, F.P.; et al. Desempenho de novilhos F1 Angus-Nelore em pastagens de Brachiaria decumbens submetidos a diferentes regimes alimentares. Revista Brasileira Zootecnia, v. 30, p.470-481, 2001.

DEL CURTO, T.; HESS, B.W.; HUSTON, J.E.; et al. Optimum supplementation strategies for beef cattle consuming lowquality roughages in the western United States. Proceedings of the American Society of Animal Science. Disponível em: http://www.asas.org. Acessado no dia: 20/08/2012.

GOES, R.H.T.B.; MANCIO, A.B.M.; LANA, R.P.; et al. Desempenho de Novilhos Nelores em Pastejo na Época das Águas: Ganho de Peso, Consumo e Parâmetros Ruminais. Revista Brasileira Zootecnia, v.32, n.1, p.214-221, 2003. 
GRINGS, E.E.; ADANS, D.C.; SHORT,R.E. Protein supplementation of stocker in the Northern great plains. Journal of Range Management, v.47, p.4, p.303-307, 1994.

JONES, A.L.; GOESTSH, C.A.; STOCKERS, S.R.; et al. Intake and digestion in cattle fed warm or cool season grass hay with or without supplemental grain. Journal Animal Science, v.66, p. 194-203, 1988.

KABEYA, K.S.; PAULINO, M.F.; DETMANN, E. et al. Suplementação de novilhos mestiços em pastejo na época de transição água-seca: desempenho produtivo, características físicas de carcaça, consumo e parâmetros ruminais. Revista Brasileira Zootecnia, v.31, p.213-222, 2002.

MINSON, D.J.; WILSON, J.R. Prediction of intake as an element of forage quality. In: GEORGE, C.; FAHEY, G.C. (Eds). Forage quality, evaluation and utilization. Madison: American Society of Agronomy, 1994, p.533-563.

MOORE, J.E.; BRANT, M.H.; KUNKLE, W.E.; et al. Effects of supplementation on voluntary forage intake, diet digestibility, and animal performance. Journal of Animal Science, v.77, p.122-135, 1999 (suppl. 2).

PARIS, W.; BRANCO, A.F.; PROHMANN, P.E.F.; et al. Suplementação energética de bovinos em pastagem de coastcross (Cynodon dactylon (L.) Pers) no período das águas. Acta Scientiarum. Animal Sciences Maringá, v. 27, no. 1, p. 109-115, Jan./March, 2005.

PAULINO, M.F.; DETMANN, E.; ZERVOUDAKIS, J.T. Suplementos múltiplos para recria e engorda de bovinos em pastejo. In: SIMPósIO DE PRODUÇÃO DE GADO DE CORTE, 2., 2001, Viçosa. Anais...Viçosa: UFV/DZO, 2001. p.187-231.

PAULINO, M.F.; MORAES, E.H.B.K.; ZERVOUDAKIS, J.T.; et al. Fontes de Energia em Suplementos Múltiplos de Auto-Regulação de Consumo na Recria de Novilhos Mestiços em Pastagens de Brachiaria decumbens durante o Período das Águas. Revista Brasileira Zootecnia, v34,n.3,p957-962, 2005.

PEREIRA, J.C.; ALMEIDA, M.S.; CECON, P.R.; et al. Dinâmica da degradação ruminal por novilhos mantidos em pastagem natural, em diferentes épocas do ano. Revista Brasileira Zootecnia, v. 31, n. 2, p. 740-748, 2002.

POPPI, D.P.; MCLENNAN, S.R. Protein and energy utilization by ruminants at pasture. Journal of Animal Science, v.73, p.278-290, 1995.

PORTO, M.O.; PAULINO, M.F.; VALADARES, S.C.F.; et al. Fontes suplementares de proteína para novilhos mestiços em recria em pastagens de capim-braquiária no período das águas: desempenho produtivo e econômico. Revista Brasileira de Zootecnia, v.38, n.8, p.15531560,2009

REIS, R.A.; RODRIGUES, L.R.A.; PEREIRA, J.R.A. Suplementação como estratégia de manejo de pastagem. In: SIMPósIo SOBRE MANEJO DE PASTAGEM, 1997 Piracicaba. Anais... Piracicaba: FEALQ, 1997. p.123-150.

SNIFFEN, C.I.; O'CONNOR, I.D.; Van SOEST, P.J. et al. A net carbohydrate and system for evaluating cattle diets: II. Carbohydrate and protein availability. Journal of Animal Science, v.70, p.3562-3577, 1992.

THIAGO, L.R.L.S.; SILVA, J.M. Suplementação de bovinos em pastejo. Campo Grande, MS: Embrapa Gado de Corte, 28 p., 2001. 
VILLELA, S.D.J. Fontes de proteína em suplementos múltiplos para bovinos em pastejo. 2004. 144f. Tese (Doutorado em Zootecnia) - Universidade Federal de Viçosa, Viçosa.

ZERVOUDAKIS, J.T.; PAULINO, M.F.; CABRAL, L.S.; et al. Suplementos múltiplos de auto controle de consumo na recria de novilhos no período das águas. Ciên. Agrotec., Lavras, v. 32, n. 6, p. 1968-1973, nov./dez., 2008 